wires of various diameters in the "as received" condition. The results are shown in the accompanying graph, and it will be seen that for wires of diameter less than about $3 / 32$ in. the value of the modulus rapidly decreases with the diameter.

Tests made on copper-plated nickel wires after heating in hydrogen to a condition of maximum magnetic permeability give a similar curve for Young's modulus, but the values are in general somewhat lower.

$$
\text { T. F. W ALL. }
$$

Department of Electrical Engineering, University, Sheffield, 1 .

$$
\text { March } 19 .
$$

${ }^{1}$ NATURE, 131, 351 (1934); also, J. Inst. Elect. King., 75 (Dec. 1934).

\section{Reflecting Power of Ultra-pure Aluminium}

ELECTRonytic polishing of metallic surfaces, which has been studied by one of us $^{1}$, does not modify the metal structure. On the contrary, it is known that classical methods of polishing greatly alter the superficial crystalline structure.

Recent work with copper has shown that surfaces polished by the electrolytic process give values of the optical constants which are reproducible, whereas this is far from being the case when surfaces of copper are prepared by mechanical polishing or by evaporation in vacuum ${ }^{2}$.

We give here the first results of an optical study of aluminium surfaces prepared from metal $99 \cdot 998$ per cent pure. An aluminium block is laminated to $7 \mathrm{~mm}$. Little strips are then cut (of about $2 \cdot 3 \mathrm{~cm} .{ }^{2}$ ) which are polished with emery paper $(0-04)$, covered with paraffin. The metal is recrystallized by heat treatment and the polish is finished on felt disks covered with a suspension of fine alumina ( 6 and 12 hours). Many of these surfaces were subjected to electrolytic polishing ${ }^{3}$ for a time sufficient to allow dissolution of the superficial pellicule formed during the final stage of the polishing. The other surfaces were finally polished on eloth disks covered with alumina (12 hours).

The reflecting powers of these two types of surfaces have been measured by the photo-electric method of Orsel ${ }^{4}$ modified by one of $\mathrm{us}^{5}$. The filtered light of a tungsten strip lamp is used $(\lambda=4500$ A.). The seven surfaces polished electrolytically have the same reflecting power within the experimental error (about 1 per cent), and the reflecting power is remarkably constant at every point of each surface. It is observed that the size of the metallic crystallites conditioned by the previous heat treatment has no influence; moreover, the surfaces even after many days exposure to atmospheric conditions, but protected against dust, do not show any alteration. Table 1 gives the results. The reflecting power is given by comparison with a polished surface of galena taken as a standard.

TABLE 1.

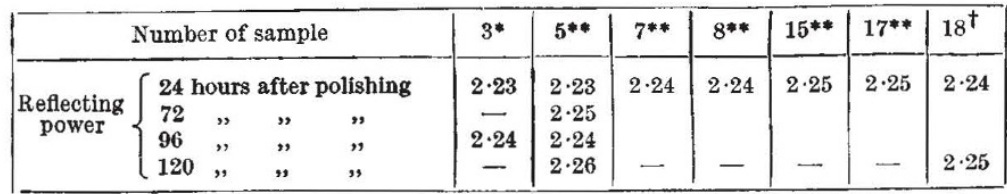

* Annealed for 20 hours at about $620^{\circ} \mathrm{C}$.

** " " " $\quad 38$ seconds at $" \quad 350^{\circ} \mathrm{C}$.
Table 2 gives the values of the reflecting powers of surfaces mechanically polished. These values are obtained immediately after polishing and they can be compared with the reflecting power of surfaces polished electrolytically.

\begin{tabular}{|c|c|c|c|c|c|}
\hline Number of sample & $1 * *$ & $2^{*}$ & $4 * *$ & $6 * *$ & $9^{* *}$ \\
\hline Reflecting power at different & 0.61 & 0.68 & 0.60 & 0.73 & 0.67 \\
\hline regions of each surface & 0.57 & $\begin{array}{l}0.66 \\
0.65\end{array}$ & $0 \cdot 62$ & $\begin{array}{l}0 \cdot 68 \\
0 \cdot 69\end{array}$ & $0 \cdot 68$ \\
\hline
\end{tabular}

\section{TABLE 2.}

** Annealed for 20 hours at about $620^{\circ} \mathrm{C}$

This table shows that the reflecting power varies notably from one surface to the other, and that even for a given surface it varies from point to point.

We conclude that ultra-pure aluminium surfaces polished electrolytically have a reflecting power well defined and reproducible. This suggests the use of such surfaces as optical standards. Moreover, such surfaces have a reflecting power greater than that of surfaces otherwise prepared. These observations show that this technique will be useful for the micrographic study of the crystalline structure of aluminium.

Laboratoire de Chimie Nucléaire,

$$
\text { P. JACQUET. }
$$

Collège de France, Paris.

\section{Laboratoire de Minéralogie, Faculté des Sciences, Toulouse.}

\section{Capdecomme.}

1 Jacquet, P., Nature, 135, 1076 (1935); C.R. Acad. Sci. Paris, 201, 1473; Bull. Soc. chimique France, (v), 3, 705 (1936).

Lowery, H., Wilkinson, H., and Smare, D. L., Phil. Mag. (vii) 22, 769 (1936); Capdecomme, L., and Jacquet, P., C.R. Acad. Sci. Paris, 204, 1415 (1937).

- Jacquet, P., C.R. Acad. Sci. Paris, 205, 1232 (1937).

4 Orcel, J., Bull. Soc. Frans. minéralogie, 54, 301 (1930).

'Capdecomme, L., C.R. Acad. Sci. Paris, 198, 462 (1934); 202. 1843 and 2061 (1936); 203, 994 (1936).

\section{A Whale Story}

MANY readers of Nature may have heard an incredible story, broadcast by the B.B.C., Regional, on January 11,1938 , in a series of talks called "Strange to Relate", about an alleged James Bartley of the Star of the East having been swallowed by a sperm whale and recovered alive from its stomach some hours after. The intelligence of readers of NATURE is such that I expect and hope few if any gave credence to the story, but of the thousands who heard it I fear many must have thought, "It must be true, or the B.B.C. would not broadcast it".

I first came across this story in "Sixty-Three Years of Engineering" by the late Sir Francis Fox, and in reviewing that book for the Journal of the Society of Engineers (October--December 1925, pp. x-xiv) I made it amply clear from in. ternal evidence that the story would not hold water. After. wards, a published letter was found from the widow of the captain of the Star of the East, in which she stated that she was on board that vessel at the time of the alleged event, and that there was not a word of truth in it. 